\title{
Synthesis of Some Heterocyclic Compounds Derived from Furfural
}

\author{
M.S.Al-Ajely ${ }^{1 \star}$ and I.M.Shaban ${ }^{2}$
}

Department of Chemistry, Education College, Mosul University, Mosul-Iraq

\author{
*Corresponding author \\ M.S.Al-Ajely, Department of Chemistry, Education College, Mosul University, \\ Mosul - Iraq. E-mail: mohamadalajelee@yahoo.com
}

Submitted: 21 Apr 2018; Accepted: 27 Apr 2018; Published: 07 May 2018

\begin{abstract}
We know that most heterocyclic compounds are drugs or co- drugs. In our investigation furfural was used as a precursor for heterocyclic synthesis, either by ring opening of furfural going to pyrimidine derivative E3 then functionalizing this pyrimidine into its derivatives E8, E10 and cyclization into oxadiazole and thiadiazoles E8, 11. Or the reaction of pyrimidine with dimedon derivatives to afford dimedino pyrimidine derivatives. The second pathway involve the synthesis of oxamyl derivative of pyrmidine E21-25 these compounds were cyclized into new oxadiazoles E24-26. The third pathway involve the synthesis of mucobromic esters E27-29 from MBA acid then these esters were converted into the correspondig lactones E30-32 and E32-36 while reacting MBA with amines affording $\mathrm{N}$-alkyland $\mathrm{N}$-amidolactams. The last pathway was the reaction MBA with methanol, sodium azide to give azidointermeddiate which was cyclized with alkene or alkynes into triazole derivatives E42-49. The synthesized compounds were characterized by IR and some ${ }^{1} H N M R$ measurements.
\end{abstract}

Keywords: Synthesis, Furfural, Heterocyclic Compounds

\section{Introduction}

Background

Furfural first time known in 1840 when Scottish scientist J.Stenhouse found that corn ash and wood treated with dilute sulfuric acid yield furfural compound Furfural was also extracted from rice straw and from palm fiber using hydrochloric acid, Quaker oat company was then succeeded in producing furfural industrially in large scale production [1-4]. After that time china and South Africa became the most countries in production of furfural. In the same year Binder et al.were also synthesized furfural from xylose and xylan [5]. In 2012 Ambalkar and Talib have succeeded in synthesizing furfural from lignocelluloses biomass as agricultural residues [6]. Warkasi and Naidoo in the same year succeeded in production of furfural from epic rap of wild mango [7].

The biological application of furfural compounds

Furfural was used as starting material for synthesizing many intermediate chemical including MCA, MBA ,4,5-Dibromo furfuraldehydle, 2-(2-furyl) [1,3] dioxane,5-nito(1,3-imidazolyl2,5-dion)-3-yl furfuraldine which was used as drag in treatment of urnary tract [8-10]. The other application of furfural derivatives is the enzymatic inhibition of brostaclanidine by benzimidiazolyl derivative $[11,12]$. While S-Alkyl-3-Aryldihydro-2- $(3 \mathrm{H})$ one derived from (MBA) was used as anti fungal agent [13]. Thiazolyl furylhydazones were prepared from alkyl furyl ketones and thiosimicarbazide using ethyl bromopyrovate. These compounds showed significant biological application [14]. Thiazole, Thiadiazole, oxadiazole and triazole compounds themselves have been found to have many biological applications and as drugs pyridine, pyrimidine and pyradizine compounds were also found to have certain biological activities as well as drags [15-23]. As it was investigated above through this introduction, furyl derivatives are biologically active compounds and so as 5, 6-membered rings had biological applications and as drugs, so in our present work we use furfural in synthesizing new derivatives of this nucleus including diazoyl, triazoyl. Thiadiazolyl, oxadiazoyl, thiazoyl and pyridine derivatives. These new compounds might have important applications as drugs. In our next work we will investigate their antibacterial screening activates as a reliminary step for drug discovery regarding these types of compounds.

\section{Experimental}

All melting points were measured using Electrothormal9300 melting point apparatus. The chemicals were supplied by Aldrich, Fluka and BDH companies'.IR spectra were measured using infrared spectrophotometer model FT (8400s) Shimadzo company.1HNMR spectra were recorded using Bruker400MHz Tocat/gaziosmanpasa University (Turkey). Mucobromic acid (MBA) was prepared according to the published paper, S-methyl isothiourinum sulfate and 5-bromo-2-methyl thio pyrimidine-4-carboxylicacid were prepared according to else were published procedures [24-26]. The acid chloride and its ester derivative were prepared following the same published procedure while compounds E4,E5 and E6 were prepared following the same or similar published procedures $[27,28]$. Compounds E7-E9 were prepared using similar procedures [29-31]. The above prepared (E4-E9) compounds were found to have the following melting points, $125-124^{\circ} \mathrm{C}$, yield of $80 \%, 235^{\circ} \mathrm{C}$, yield of $75 \%, 176-178^{\circ} \mathrm{C}$, yield of $30 \%$, oil, yield $60 \%, 63-65^{\circ} \mathrm{C}$, yield 
$53 \%, 105-107^{\circ} \mathrm{C}$, yield $60 \%$, oil, yield $65 \%, 119-121^{\circ} \mathrm{C}$, yield $60 \%$ and $150-152^{\circ} \mathrm{C}$, yield $50 \%$ respectively Compounds E37a was prepared following the same published procedure, $\mathrm{E}_{37 \mathrm{~b}}$ was prepared according to a similar published procedure with mp of $70-72^{\circ} \mathrm{C}$, yield $80 \%$. These intermediate compounds were checked by IR after purification $[32,33]$.

Synthesis of 2-Methyl sulfonyl-4-(N-formylcarbohydrazido)-5bromo pyrimidine $\left(\mathbf{E}_{10}\right)[34]$.

E7 compound $(0.01 \mathrm{md} .3 \mathrm{gm})$ was dissolved in $20 \mathrm{ml}$. of formic acid. The mixture was then refluxed for $30 \mathrm{~min}$; evaporation of the solvent, the solid product was collected and recrystallized from ethanol giving wellow crystals, mp $160-162^{\circ} \mathrm{C}$, yield $70 \%$.

Synthesis of 2-Methyl sulfonyl-5-bromo-6-(1,3,4-thiuzol-5-yl)1,3-pyrimidine $\left(\mathrm{E}_{11}\right)$ [34].

Compound E10 (0.01 mol, 3.2g.) was dissolved in $5 \mathrm{ml}$. Xylene. To this mixture $(0,01 \mathrm{~mol} .2 .2 \mathrm{~g})$ phosphorouspenta sulfide was added .The mixture was stirred and refluxed for $60 \mathrm{~min}$. evaporation of the solvent and addition of 10 mil of water and extracting the product with chloroform. The chloroform was then evaporated giving brown precipitate. Recrystallization from ethanol affording pale-brown crystals, mp. $140-142^{\circ} \mathrm{C}$, yield $53 \%$.

Synthesis of 3-(4-Aryl amino) 5,5-dimethyl cyelonex-2-enone $\left(\mathbf{E}_{12-14}\right)$ [35].

Substituted aniline $(0.05 \mathrm{~mol}$.) and dimedon $(0.05 \mathrm{~mol})$ were dissolved in dry benzene. The mixture was refluxed for $3 \mathrm{~h}$. The progress of the reaction was monitored by TLC.Aftercompletion; the reaction mixture was left to cool to r.t, mixed with ether and stirred for 15-20 min, filtered and washed with ether and dried then crystallized from it. The melting point were found $207-208^{\circ} \mathrm{C}, 75 \%$ yield ; $160-162^{\circ} \mathrm{C}$, yield 75 and $200-202^{\circ} \mathrm{C}$, yield $73 \%$ as yellowish to white ,Brown and yellow products respectively.

Synthesis of 5-Bromo-N-(4-aryl)-N-(5,5-dimethyl-3-oxo cyclo hex-1-enyl)-2-(methyl thio) pyrimidine-4-carboxamide $\left(\mathrm{E}_{15-17}\right)[36]$. Compounds $\left(\mathrm{E}_{12-14}\right), 0.01 \mathrm{~mol}$. were dissolved in $25 \mathrm{ml}$. of dry benzene. To this mixture was then added $(0.01 \mathrm{~mol} ., 1 \mathrm{~g}$. $)$ of TEA. The find mixture was then added to mixture of compound E4 in $25 \mathrm{ml}$ of dry benzene gradually with continuous stirring under dry condition at r.t. The mixture was then refluxed for $24 \mathrm{~h}$. And left to cool, filtered and washed with $50 \mathrm{ml}$. of water. The organic layer was extracted and dried using an hydrous Na2SO4. The solvent was evaporated, the residue was crystallized from ethanol. Melting points of the above compounds $264-266^{\circ} \mathrm{C}$ yield $60 \%, 217-218^{\circ} \mathrm{C}$, yield 64\% with Brown, Brown and red respectively.

Synthesis of substituted amidoxime $\left(\mathrm{E}_{18-20}\right)$ [34].

Nitrile compound (acetonitrile or valeronitrile or benzyl nitrile) (0.1 mol.) was dissolved in $100 \mathrm{mil}$ of $50 \%$ ethanol. To this solution $21.2 \mathrm{~g}$.of sodium carbonate was added then $27.8 \mathrm{~g}$. of hydroxyl amine hydrochloride. The final mixture was refluxed on water bath for 90 min, evaporation of the solvent and the residue was collected and re crystallized from ethanol affording the find crystals as white , coreless oil and yellow having mp $132-134^{\circ} \mathrm{C}$, yield $72 \%$, oily and $65-67^{\circ} \mathrm{C}$ yield $75 \%$ respectively .

Synthesis of 2-methyl thio-5-bromo-6-(substituted amino oxamyl)-1,3-Pyrimidine-4-carboxylate $\left(\mathrm{E}_{21-23}\right)$

Amidoxime compound $\left(\mathrm{E}_{18-20}\right), 0.002 \mathrm{~mol}$. In $10 \mathrm{mil}$ of chloroform was mixed with compound E3 (0.0022 mol. , 0.5g.) of Dcc. The mixture was stirred for $60 \mathrm{~min}$ at r.t. The final mixture was then filtered and the residue was re crystallized from benzene / petroleum ether $\left(80-60^{\circ} \mathrm{C}\right)$. Affording white crystal of the above compounds with m.p $185-187^{\circ} \mathrm{C}$, yield $65 \%, 190-192^{\circ} \mathrm{C}$, yield $70 \%$ and $194-$ $196^{\circ} \mathrm{C}$, yield $73 \%$ respectively.

Synthesis of 2-methyl thio-5-bromo-6-(3-substituted 1,2,4) oxa diazole)-5-yl-1,3- pyrimidine $\left(\mathbf{E}_{24-26}\right)$

Compound (E21-23), 0.1 mol. was mixed with $25 \mathrm{ml}$. of dry DMSO. The mixture was there refluxed for $5 \mathrm{~h}$, cool and filtered. The residue was re crystallized from water affording Brown crystals of the above compounds having mp $140-142^{\circ} \mathrm{C}$, yield $60 \%, 100-102^{\circ} \mathrm{C}$, yield $65 \%$ and $180-182^{\circ} \mathrm{C}$, yield $68 \%$ respectively.

Synthesis of 5-substituded -3,4-dibromo crotono lactone carboxyl $\operatorname{ate}\left(\mathrm{E}_{27-29}\right)$.

Compound (E0.02 mol.) was dissolved in $100 \mathrm{ml}$ of dry benzene was added $(0.02 \mathrm{~mol}$.) of compound (acetyl chloride or 4-nitrobenzoyl chloride or benzoyl chloride). The final mixture was refluxed with continuous stirring for $24 \mathrm{~h}$. Under dry condition, cooled and the solvent was evaporated under reduced pressure, giving the final product as oil for $\mathrm{E}_{27}$ and white solid for $\mathrm{E}_{28} \mathrm{mp}$. of $118-120^{\circ} \mathrm{C}$, yield $72 \%$ while yellow for $\mathrm{E}_{29} \mathrm{~m} . \mathrm{p}, 152-154^{\circ} \mathrm{C}$, yield $74 \%$.

Synthesis of (5-substituded amino) -3,4-dibromo crotono lactone ( $\left.\mathbf{E}_{30-32}\right)$

Compound ( $E_{27} 0.01 \mathrm{~mol}$.) dissolved in $50 \mathrm{ml}$ of toluene was mired with (Ethyl amine or isopropyl amine orcyclohexyl amine) the mixture was stirred for $20 \mathrm{~h}$. at r.t. evaporation of the solvent afford the titled compounds in which $\mathrm{E}_{30}$ was oily while $\mathrm{E}_{31}$ and $\mathrm{E}_{32}$ were yellow solid products after recrystallitation from ethanol. $\mathrm{mp}$ of $\mathrm{E}_{31}$ was $96-98^{\circ} \mathrm{C}$, yield $65 \%$ while for compound $\mathrm{E}_{32} 102-1040 \mathrm{C}$ yield $62 \%$.

Synthesis of 2-methoxy-3-N-substituded triazolyl-4-bromo crotono lactone $\left(\mathrm{E}_{33-36}\right)$ [37].

Compound $\left(\mathrm{E}_{46} 0.005 \mathrm{~mol}\right.$.) was dissolved in $30 \mathrm{ml}$ of dry acetone this solution was then added to a solution of DMAD or cyclohexene or Trans 1,2-dichloro ethylene $0.01 \mathrm{~mol}$. The final mixture was refluxed for $12 \mathrm{~h}$. under dry condition. Evaporation of the solvent, removed of the solvent afford a solid product which was recrystallized from ethanol. mp $102-104{ }^{\circ} \mathrm{C}$, yield $65 \%$ as brown crystals, $140-142$ ${ }^{\circ} \mathrm{C}$, yield $66 \%$ as gray crystals, $110-112{ }^{\circ} \mathrm{C}$ yield $60 \%$ gray crystals respectively.

Synthesis of 3,4-dibromo-5-hydroxy-1-substituted -3-pyroline2-one $\left(\mathrm{E}_{37-40}\right)$

Compound $\mathrm{E}_{37 \mathrm{a}}(0.003 \mathrm{~mol} ., 0.8 \mathrm{~g})$ dissolved in $25 \mathrm{ml}$ of dioxane was gradually added to a cold solution of $0.006 \mathrm{~mol}$. of amine dissolved in $10 \mathrm{ml}$ of dioxane. The mixture was stirred for $15 \mathrm{~h}$ at r.t. After the completion of the reaction (monitored by $\mathrm{TlC}$ ) $25 \mathrm{ml}$ of water was then added and extracted by $100 \mathrm{ml}$ of $\mathrm{CH}_{2} \mathrm{Cl}_{2}$. The organic layer washed with $\left({ }^{1} \mathrm{NHCl}\right)$ then with saturated $\mathrm{NaCl}$ solution, charcool. And filtered. Evaporation of the solvent to minimum amount and addition of n-hexane resulted in to the precipitation of the product which was then recrystallized from chloroform affording the final product for $\mathrm{E}_{38} \mathrm{mp}$. of $102-103^{\circ} \mathrm{C}$ as white crystals $72 \%$ yield while for $\mathrm{E}_{39} \mathrm{mp} 118-120^{\circ} \mathrm{C}$ as yellowish white crystals, $55 \%$ yield and $\mathrm{E}_{40} \mathrm{mp} 177-179^{\circ} \mathrm{C}, 63 \%$ yield as yellowish white product. 
Synthesis of -1- substituted amindo-3,4- dibrome-5-hydroxy-3pyroline-2-one $\left(\mathrm{E}_{41-44}\right)$

Compound $\mathrm{E}_{1}(0.003 \mathrm{~mol} ., 0.77 \mathrm{~g})$ was dissolved in $20 \mathrm{ml}$ of ethanol, to this solution was added $(0.03 \mathrm{~mol})$ of methyl urea or ethyl urea or thiouria or phenyl urea. The final mixture was refluxed for $3 \mathrm{hr}$ in a water bath. Evaporation of the solvent under reduced pressure to a minimum amount and addition of $50 \mathrm{ml}$ of water then extraction with $100 \mathrm{ml} \mathrm{CH}_{2} \mathrm{Cl}_{2}$, dried on $\mathrm{Na}_{2} \mathrm{So}_{4}$ anhydrous and evaporation of the solvent resulted into the formation of the precipitate which was recrystallized from chloroform forming $\mathrm{E}_{41}$ as white crystal, mp $241-243^{\circ} \mathrm{C}, 70 \%$ yield, $\mathrm{E}_{42}$, white crystal $\mathrm{mp} 181-183^{\circ} \mathrm{C}, 75 \%$ yield while $\mathrm{E}_{43}$ formed as yellow crystal m.p $159-161^{\circ} \mathrm{C}, 55 \%$ yield and $\mathrm{E}_{44}$ as red crystal mp $145-148^{\circ} \mathrm{C}, 63 \%$ yield .

Synthesis of 3,4-dibromo-5-methoxy crotono lactone $\left(\mathrm{E}_{45}\right)$ Conc. sulfuric acid $(0.1 \mathrm{ml})$ was added to a solution of $(0.025 \mathrm{~mol}$, $6.5 \mathrm{~g}) \mathrm{E}_{1}$ dissolved in $10 \mathrm{ml}$ methanol. The final mixture was refluxed for $24 \mathrm{hr}$. After completion $30 \mathrm{ml}$ of water was added the compound was extracted with benzene, washed with saturated soln. of sodium carbonate, dried on anhydrous $\mathrm{Na}_{2} \mathrm{SO}_{4}$, Evaporation of the solvent under reduced pressure resulted into the formation of an oily yellow compound which was used in next step.

Synthesis of -4-azido-3-bromo-5-methoxy crotono lactone $\mathrm{E}_{46}$ Compound $\mathrm{E}_{45}(0.0413 \mathrm{~mol} .11 .23 \mathrm{~g})$ dissolved in $75 \mathrm{ml}$ methanol .To this solution $(0.0413 \mathrm{~mol} ., 2.7 \mathrm{~g})$ of sodium a zide was added. The mixture was stirred at r.t. for $60 \mathrm{~min}$, addition of water cause to the formation of white precipitate, washed several times with cold water, mp $70-72^{\circ} \mathrm{C}, 80 \%$ yield.

Synthesisof-2-methoxy-3-N-substituted triazolyl-4-bromocrotono lactone $\left(\mathrm{E}_{47-49}\right)$

A mixture of compound $\mathrm{E}_{46}(0.005 \mathrm{~mol}, 1.17 \mathrm{~g})$ dissolved in $30 \mathrm{ml}$ of dry acetone and $0.01 \mathrm{~mol}$ of alkyne or alkene compound were refluxed for $12 \mathrm{hr}$ under dry conditions. The mixture was cooled ,Evaporation of the solvent affording final crude precipitate which was recrystallized from ethanol . the following physical properties was obtained $: \mathrm{E}_{47}$ as brown crystals $\mathrm{mp} 102-105^{\circ} \mathrm{C}$, yield $65, \mathrm{E}_{48}$ gray crystals $\mathrm{mp} 140-143^{\circ} \mathrm{C}, 66 \%$ yield and $\mathrm{E}_{49}$ as gray crystasmp $110-113^{\circ} \mathrm{C}, 60 \%$ yield

\section{Results and Discussion}

Hydrazide comp $\left(\mathrm{E}_{7}\right)$ was prepared from its ester $\left(\mathrm{E}_{6}\right)$. This compound was checked by IR which showed the following absorption bands $1651 \mathrm{~cm}^{-1}$ for $\mathrm{C}=\mathrm{O}, 3188-3340 \mathrm{~cm}^{-1}$ for $\mathrm{NH}, 1632 \mathrm{~cm}^{-1}$ for $\mathrm{C}=\mathrm{N}$ and the aromatic $\mathrm{C} \ldots \mathrm{C}$ absorbed at $1550 \mathrm{~cm}^{-1}, \mathrm{~S}=\mathrm{O}$ at 118,1323 . Compound E8 IR data are $3310,3165 \mathrm{~cm}^{-1}$ for stretching vibration of $\mathrm{NH}, 1637 \mathrm{~cm}^{-1}$ for $\mathrm{C}=\mathrm{N}, 1526 \mathrm{~cm}^{-1}$ for AromaticC...C, $1286 \mathrm{~cm}-1$ for $\mathrm{C}=\mathrm{S}, 1193,1343$ for $\mathrm{S}=\mathrm{O}$ group.

Compound $\mathrm{E}_{9}$ was prepared from the cyclization of the corresponding thiosimicarbazide using $\mathrm{AgO}$ reagent. The compound showed the following absration bands, $3234 \mathrm{~cm}^{-1}$ for $\mathrm{NH}, 1178-1254$ $\mathrm{cm}^{-1}$ for C-O-C, 1601 the carbonyl group and thion belongs to thiosimicarbazide.

2-methy sulfonyl-5-bromo-6-(2-1,3,4-thiadiazole)-5-yl-1,3pyrimidine $\left(\mathrm{E}_{11}\right)$ was prepared from the reaction of $\mathrm{E}_{7}$ with formic acid to afford compound $\mathrm{E}_{10}$ which was cyclized into the titled compound. Compound $\mathrm{E}_{10}$ was characterized by the following IR absorption bands $1689 \mathrm{~cm}^{-1}$ for $\mathrm{C}=\mathrm{O}$ of formaide and $3200 \mathrm{~cm}^{-1}$ for NH. While the final compound E11was characterized by IR absorption band at 1623 for $\mathrm{C}=\mathrm{N}$ stretching vibration and 863,1153 $\mathrm{cm}^{-1}$ for C-S-C symmetric and asymmetric types.

5-bromo-N-(4-Aryl)-N-(S,5, dimethyl-3-oxo-1-cyclohexenyl-2methyl thio pyrimidine-4-carboxanide $\left(\mathrm{E}_{15-17}\right)$

The first step of preparing of these compounds was the formation of $\mathrm{E}_{12-14}$ through the reaction of substituted aniline with dime done. These compounds were characterized by IR spectra. The main characteristic bands were 3061-3241 $\mathrm{cm}^{-1}$ belongs to NH, 1609$1618 \mathrm{~cm}^{-1}$ belongs to $\mathrm{C}=\mathrm{O}$ stretching and $\mathrm{C} \ldots \mathrm{C}$ aromatic apparel at $1459-1593 \mathrm{~cm}^{-1}$.

The second step involves the reaction of $\mathrm{E}_{12-14}$ with compound $\mathrm{E}_{4}$ as shown in schem 1 . The final compounds were characterized by the following IR absorption bands $2950,2960 \mathrm{~cm}^{-1}$ belongs to aliphatic $\mathrm{C}-\mathrm{H}$ stretching, $1665 \mathrm{~cm}^{-1}$ and $1735 \mathrm{~cm}^{-1}$ belong to $\mathrm{C}=\mathrm{O}$ while amide $\mathrm{C}=\mathrm{O}$ appeared at $1651,1671 \mathrm{~cm}^{-1}$. The aromatic $\mathrm{C}$...C and $\mathrm{C}=\mathrm{N}$ appeared within the range of $1601-1627 \mathrm{~cm}^{-1}$ which were undistinguishable from the conjugated $\mathrm{C}=\mathrm{C}$ and the kenotic band.

\section{2-methyl thio-5-Bromo-6-(3-Substituted-1, 2, 4-Oxadiazole-5-yl} 1, 3-pyrimidine $\left(\mathrm{E}_{24-26}\right)$

The compounds were also prepared by three steps. Step one is the preparation of amidoxirne compounds $\mathrm{E}_{18-20}$ from the reaction of some nitrile compounds with hydroxyl amino hydrochloride. Comps. $\mathrm{E}_{18-20}$ were confirmed by IR spectra and the melting points in comparison with that published [28-38]. The second step is the reaction of these amidoxime compounds with $\mathrm{E}_{3}$ compound in presence of DCC as shown in scheme 1. The IR spectra of these compounds characterized by the following absorption bands 3244$3327 \mathrm{~cm}^{-1}$ for $\mathrm{NH}, 1710-1718 \mathrm{~cm}^{-1}$ for $\mathrm{C}=\mathrm{O}$ ester with $\mathrm{C}=\mathrm{N}$ appeared at $1658-1670 \mathrm{~cm}^{-1}$ and the aromatic appeared at $1425-1602 \mathrm{~cm}^{-1}$ while $\mathrm{C}-\mathrm{O}$ appeared at $1018-1140 \mathrm{~cm}^{-1}$. The third step in synthesizing the above compounds $\left(\mathrm{E}_{24-26}\right)$ was the cyclization into the corresponding final products. These final compounds were characterized by IR and the main absorption bands were as following : $1616-1653 \mathrm{~cm}^{-1}$ for $\mathrm{C}=\mathrm{N}, \mathrm{C} \ldots$. C aromatic at $1432-1596 \mathrm{~cm}^{-1}$ while $\mathrm{N}-\mathrm{O}$ at $1250-1311$ $\mathrm{cm}^{-1}$ and $\mathrm{C-O}$ at $1087-1045 \mathrm{~cm}^{-1}$.

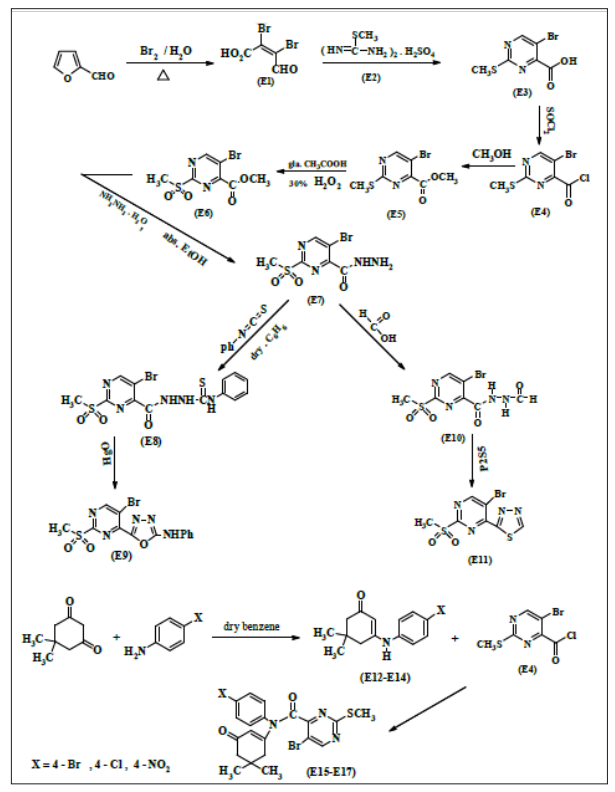

Scheme 1 
5-subsituted amino 3, 4-dibromo crotono lactone $\left(\mathrm{E}_{30-32}\right)$ These compounds were synthesized from the reaction of compound E1 with each of (acetyl chloride, benzyl chloride and 4-nitro benzyl chloride) as mentioned in the experimental part of this work and as shown in scheme 2 . The products were characterized by the following IR absorption bands: $1764-1798 \mathrm{~cm}^{-1}$ for lactone $\mathrm{C}=\mathrm{O}$ and at $1682-1750 \mathrm{~cm}^{-1}$ belongs to $\mathrm{C}=\mathrm{O}$ stretching of ester. The aromatic C...C was appeared within the range of $1450-1588 \mathrm{~cm}^{-1}$ while C-O stretch appeared within $1120-1144 \mathrm{~cm}^{-1}$. These products $\mathrm{E}_{27-29}$ were allowed to react with ethyl amine, isopropyl amine and cyclohexyl amine affording the titled compounds. These final compounds were characterized by the following absorption bands;3310-3368 $\mathrm{cm}^{-}$ ${ }^{1}$ related to $\mathrm{NH}$ stretch , $1765-1775 \mathrm{~cm}^{-1}$ to $\mathrm{C}=\mathrm{O}$ lactone while $\mathrm{C}=\mathrm{C}$ appeared at $1615-1621 \mathrm{~cm}^{-1}, \mathrm{C}-\mathrm{O}$ at $1119-1125 \mathrm{~cm}^{-1}$ and $\mathrm{C}-\mathrm{N}$ at $1049-1090 \mathrm{~cm}^{-1}$.

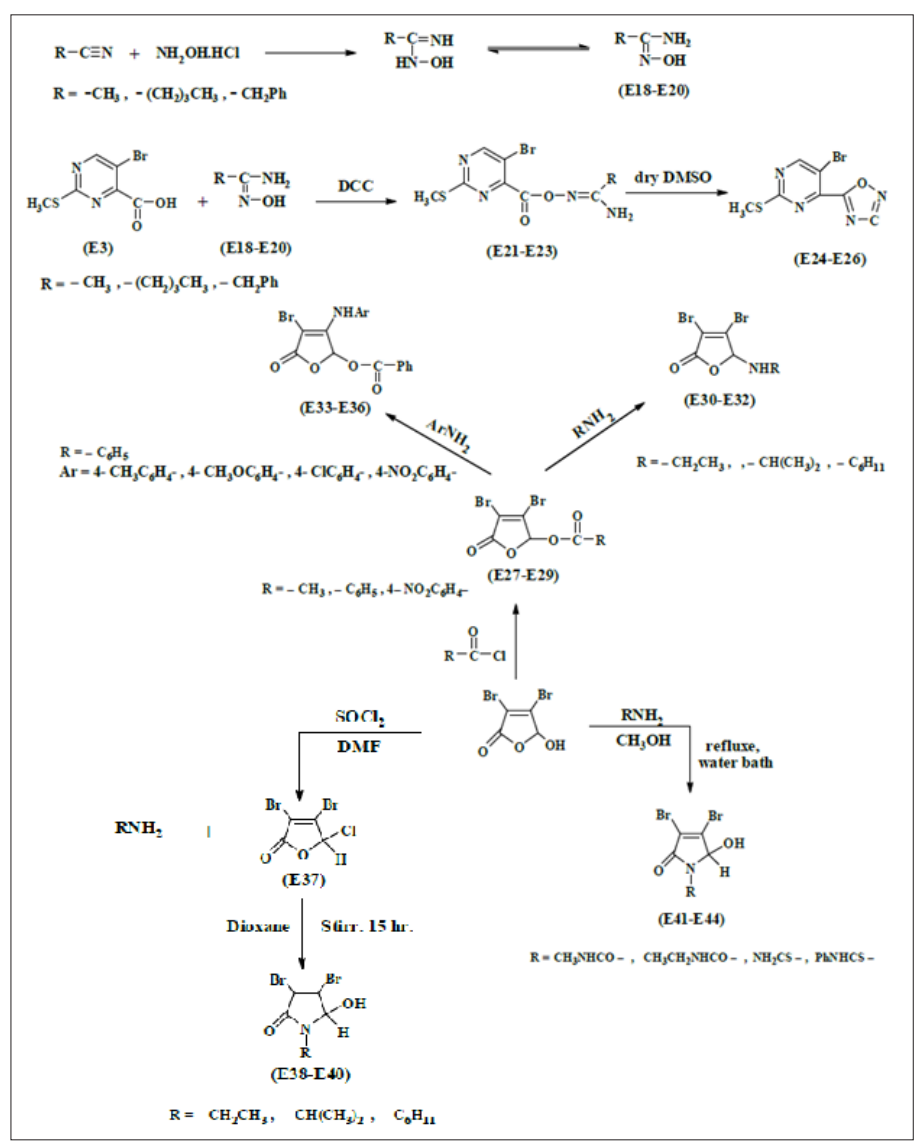

Scheme 2

4-Aromatic amino-3-bromo-5-benzeyl oxy crotono lactone $\left(\mathrm{E}_{33-36}\right)$ These compounds were synthesized by the nucleophilic displacement of-5-bromo substituted of the lactone ring with the aromatic amino group. The compounds were characterized by the following IR absorption bands : $3132-3394 \mathrm{~cm}^{-1}$ belongs to $\mathrm{NH}$ stretch , 1743$1779 \mathrm{~cm}^{-1}$ for $\mathrm{C}=\mathrm{O}$ lactone, $1738-1685 \mathrm{~cm}^{-1}$ for $\mathrm{C}=\mathrm{O}$ ester, $\mathrm{C}=\mathrm{C}$ non aromatic appeared of $1610-1618 \mathrm{~cm}^{-1}$ while the aromatic $\mathrm{C}=\mathrm{C}$ of $1426-1611 \mathrm{~cm}^{-1}$ and C-O at $1180-1192 \mathrm{~cm}^{-1}$.

${ }^{1} \mathrm{HNMRspectrumof}$ compound $\mathrm{E}_{33}$ showed the following $\delta$ signals: 8.58-9.71ppm $5 \mathrm{H}$ aromatic protons of the benzyl group,7.45$7.47 \mathrm{ppm} \mathrm{AB}$ quartet for $\mathrm{p}$-methyl aromatic ring Protons , $6.8 \mathrm{pp}(\mathrm{s})$ $1 \mathrm{H}$ of lactonic protons , $3.57 \mathrm{ppm} 1 \mathrm{H}$ for $\mathrm{NH}$ proton and singlet $3 \mathrm{H}$ at $2.5 \mathrm{ppm}$ assigned for $\mathrm{CH}_{3}$ of the phenyl ring which is coinside with the DMSO(solvent) signal.

1HNMR spectrum of compound E36 showed the following resonating signals:

At $\delta 8.26 \mathrm{ppm} 4 \mathrm{H}$ (q) assigned for aromatic ring at position 4 of lactone ring appeared as $\mathrm{AB}$ quartet, $\delta 6.6,6.94 \mathrm{ppm} 6 \mathrm{H}(\mathrm{m})$ for the aromatic benzoyl group. and at $\delta 5.141 \mathrm{H}(\mathrm{s})$ for $\mathrm{NH}$.

3, 4-Dibromo-5-hydroxy-1-1substitued -3-pyroline-2-one $\left(\mathrm{E}_{37-40}\right)$ These compounds were synthesized in two steps. Step one include the preparation of 3,4-Dibromo-5-chloro crotono lactone $\left(\mathrm{E}_{37 \mathrm{~b}}\right)$ from the reaction of compound (E1) with thionyl chloride, this compound was characterized using IR spectral data and its melting point which was the same as the published one32. In step two compound E37a was allowed to react with either ethyl or cyclohexyl or isoproxyl amine. The reaction involve ring opening and closer forming the above titled compounds see scheme 2 .These final compounds were characterized by IR spectroscopy which showed the following absorption bands : $3257-3356 \mathrm{~cm}^{-1}$ for $\mathrm{OH}, 1720-1741 \mathrm{~cm}^{-1}$ for $\mathrm{C}=\mathrm{O}, \mathrm{C}=\mathrm{C}$ at $1631-1641 \mathrm{~cm}^{-1}$ while $\mathrm{C}-\mathrm{O}$ at $1219-1240 \mathrm{~cm}^{-1}$ and $\mathrm{C}-\mathrm{N}$ at $1093-1111 \mathrm{~cm}^{-1},{ }^{1} \mathrm{HNMR}$ for compound $\mathrm{E}_{38}$ showed the following $\delta$ signals: $1.10 \mathrm{ppm} 3 \mathrm{H}(\mathrm{t})$ for $-\mathrm{CH}_{3}$ group, $2.51 \mathrm{ppm} 2 \mathrm{H}$ for $\mathrm{CH}_{2}$ protons, $3.48 \mathrm{ppm}(\mathrm{s}) 1 \mathrm{H}$ for $\mathrm{OH}$ proton, $5.44 \mathrm{pp}(\mathrm{s}) 1 \mathrm{H}$ for ring proton.

1-Substituted amido -3, 4-dibromo-5-hydroxy-3-pyroline-2-one $\left(\mathrm{E}_{41-44}\right)$

These compounds were prepared by reacting mucobromic acid E1 with methyl urea, ethyl urea and phenyl urea see scheme 2 . The final compounds were characterized by IR,1HNMR spectroscopy.

IR spectral data showed the following absorption bands: $3350-3423 \mathrm{~cm}^{-1}$ for $\mathrm{OH}, 3161-3282 \mathrm{~cm}^{-1}$ for $\mathrm{NH}, 1710-1710 \mathrm{~cm}^{-1}$ for $\mathrm{C}=\mathrm{O}$ lactam, $\mathrm{C}=\mathrm{C}$ appeared of $1610-1615 \mathrm{~cm}^{-1}$ and $\mathrm{C}-\mathrm{O}$ at $1230-1259 \mathrm{~cm}^{-1}$ while $\mathrm{C}-\mathrm{N}$ at $1060-1191 \mathrm{~cm}^{-1}$.

1HNMR for compound $\mathrm{E}_{42}$ showed the following resonating signals $: \delta$ value $1.15 \mathrm{ppm}(\mathrm{t}) 3 \mathrm{H}$ for $\mathrm{CH} 3$ protons, $2.51 \mathrm{ppm}(\mathrm{s})$ for $(\mathrm{OH})$, $2.8 \mathrm{ppm}(\mathrm{s}) 1 \mathrm{H}$ for lactons proton, $3.35 \mathrm{ppm}$ (q) $2 \mathrm{H}$ for $\mathrm{CH} 2,8.94$ ppm (s) $1 \mathrm{H}$ for $\mathrm{NH}$. while ${ }^{1} \mathrm{HMR}$ for compound $\mathrm{E}_{44}$ showed the following signals in $\delta$ value $: 2.51 \mathrm{ppm}(\mathrm{s}) 1 \mathrm{H}$ for $\mathrm{OH}$ coinside with the DMSO signal, $3.32 \mathrm{ppm}$ (s) $1 \mathrm{H}$ for lactono rig proton, 7.3-7.4 ppm (m) $5 \mathrm{H}$ for benzene ring protons, $9.66 \mathrm{ppm}(\mathrm{s}) 1 \mathrm{H}$ for NH proton [38].

2-methoxy-3-substuted triazolyl-4-Bromo crotono lactone $\left(\mathrm{E}_{45-49}\right)$ These compounds were synthesized by two steps, see scheme 3, the first one involves the preparation of 3, 4-dibromo-5-methoxy crotono lactone $\mathrm{E}_{45}$ by methylation of $\mathrm{E}_{1}$ with methanol in sulfuric acid while compound $\mathrm{E}_{46}$ was obtained from the reaction of $\mathrm{E}_{45}$ with sodium azide. This intermediate was characterized by IR through the following absorption bands: $1237 \mathrm{~cm}^{-1}$ for azide group, $1772 \mathrm{~cm}^{-1}$ lactone $\mathrm{C}=\mathrm{O}, 1639 \mathrm{~cm}^{-1}$ for $\mathrm{C}=\mathrm{C}$ and $1304 \mathrm{~cm}^{-1}$ for $\mathrm{C}-\mathrm{O}$.

In step 2 compound $\mathrm{E}_{46}$ was allowed to react with dimethyl acetylene carboxylate,cyclohexene and trans 1,2-dichloro ethylene respectively affording the final compounds $\mathrm{E}_{47-49}$. These compounds were characterized by the following IR spectral data: 1734-1776 $\mathrm{cm}^{-1}$ for $\mathrm{C}=\mathrm{O}$ lacton, $1608-1629 \mathrm{~cm}^{-1}$ for $\mathrm{C}=\mathrm{C}, 1377-1438 \mathrm{~cm}^{-1}$ for $\mathrm{N}=\mathrm{N}$ while $\mathrm{N}-\mathrm{N}$ appeared at $1204-1253 \mathrm{~cm}^{-1}$. 


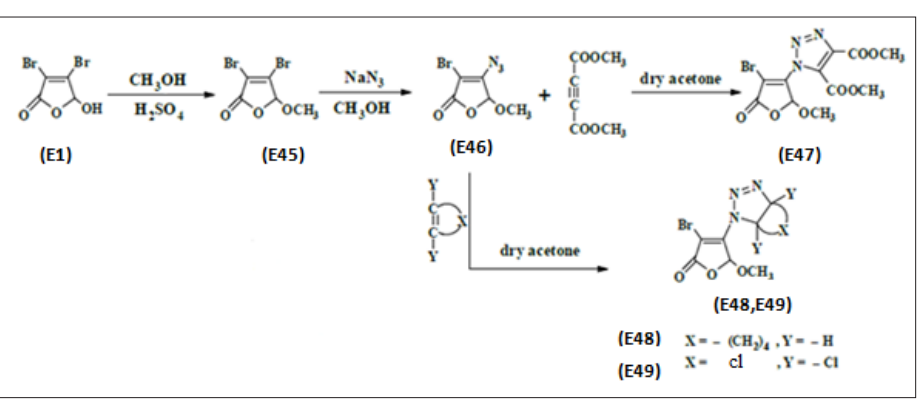

\section{References}

1. F. Carrasco (1993) Wood and Fiber Science 25: 91-102.

2. M. Sashikala, H.K. Ong (2007) "Synthesis and identification of furfural from rice straw", J.Trop.Agric and Fd.Sc 35: 165-172.

3. J.A. Yabefa, C.S. Ajinomoh, I.A. Mohammed, D. Wankasi (2010) "Biomass - Furfural basid ion exchange resins. Preparation of polymeric composition", Scholars Research Library 2: 256-260.

4. W.D. Jong, G. Marcotullio (2010) "Overview of biorefineriesbasid on Co-production of furfural, Existing concepts and novel developments", International Journal of Chemical Reactor Engineering 8: 3-5.

5. J.B. Binder, J.J. Blank, A.V. Cefali and R.T. Raines (2010) "Synthesis of furfural from xylose and xylan", ChemSusChem 3: 268-1272.

6. V.U. Ambalkar, M.I. Talib (2012) "Synthesis of furfural from lignocellulosic biomass as agricultural residues", International Journal 1: 30-36.

7. D. Wankasi, E.B. Naidoo (2012) "Furfural production from the epic rap of wild mango (irvingia species) fruits by acid catalyzed hydrolysis" Am. J. Food and Nutr 2: 47-50.

8. S. Beattie, I.M. Heibron, F. Iraving (1932) "Dicarbocyanines anew series of cyanine dyes”, J. Chem. Soc., 264.

9. Ya.L. Gol'dfarb, L.D. Tarasova (1965) "Bromination products of furfural", Russian Chemical Bulletin 14: 1041-1042.

10. T.A. Stroganova, A.V. Butin, L.N. Sorotskaya, V. G. Kul'nevich (2000) "(Aryl) (2- furyl) alkanes and their derivatives, 20.1 Synthesis of symmetric bis- and tris (2-furyl) methane's", Arkat USA, Inc 641-659.

11. M. Baumann, I.R. Baxendale, S.V. Ley, N. Nikbin (2011) “An overview of the key routes to the best selling 5- membered ring heterocyclic pharmaceuticals", Beilstein J.Org. Chem 7: 442-495.

12. I. Bruno, R. De Simone (2010) "Design, Synthesis and pharmacological studies of structural analogues modeled on bioactive natural products", PhD. Thesis, University of Salerno.

13. R.G.Bombarelli, M.G.Péres, J.A.Valgañón, I.F.C.Camacho, E.Calle et al. (2011),'DNA-Damaging disinfection byproducts: Alkylation mechanism of mutagenic mucohalicacids", Environ. SciTechnol 45: 9009-9016.

14. C. Simon, D.A. Melissa., D.M. Celeste, S. Daniela and Y.Matilda (2013) Arch. Pharm. Chem. Life Sce 346: 17-22.

15. M.Kundu, B.Singh, T.Ghosh, J.Singh, T.K.Maity (2011) "Synthesis and anticancer activity of 3,5-Diaryl-1,2,4Oxadiazole", Ind.J.Pharm. Edu. Res 45: 267-271.

16. El-SayedTarik Ali, El-Kazak Azza Mohammed (2010) Synthesis and antimicrobial activity of some new 1,3-thiazoles, 1,3,4-thiadiazoles, 1,2,4-triazoles and 1,3-thiazines incorporating acridine and 1,2,3,4-tetrahydroacridine moieties, European
Journal of Chemistry 1: 6-11.

17. K.P.Harish, K.N.Mohan, L.Mallesha, (2013), "Synthesis of pyrazine substituted1, 3, 4-Thiadiazole derivatives and their anticonvulsant activity", Organic Chemistry International 1-8.

18. Y. Xian-Hui, X. Lu, L.Xi, T.Z.Ting, Z.Hui et al. (2012) Bioorganic and Medicinal Chemistry 20: 2789-2795 .

19. R.Kumar, M.S.Yar, B.Srivastava (2014) "Synthesis and biological screening of some novel oxadiazole derivatives",Int.J.Pharm. Tech.Res 6: 316-322

20. S.S.Makone, D.B.Vyawahare (2013) "Sodium perchlorate catalyzed synthesis of Hantzsch1,4- dihydropyridine derivatives under mild conditions", Int. J. Chem. Tech Res 5: 1550-1554.

21. J.K.Gupta, P.K.Sharma, R.Dudhe, A.Chaudhary, P.k.Verma (2010) "Synthesis, Analgesic and ulcerogenic activity of novel pyrimidine derivative of coumarin moiety", Analele Universitățidin București 19: 9-21.

22. N.A. Abdel Latif, M.M. Saeed, N.S. Ahmed, R.Z. Batran, N.R.A.El-Mouhty (2014) "Synthesis of some pyridine, pyrimidine and cyclohexenone derivatives as antibacterial agents", International Journal of Innovative Research in Science, Engineering and Technology" 3: 2319- 8753.

23. C.F.H. Allen, F.W. Spangler (1947) "Mucobromic acid" 27, 60.

24. F Bellina, R Rossi Bellina, Fabio; Rossi, Renzo (2007) An efficient and inexpensive multigram synthesis of 3, 4-dibromoand 3, 4-dichlorofuran-2 (5H)-one, Synthesis 2007: 1887-1889.

25. J.F.W.Mcomi, I.M.White (1953) "Pyrimidine Part VI, 5-bromo pyrimidine", J. Chem. Soc., 3130.

26. G.A.Grant, G.V.Seemanno, S.O.Winthrap (1956) "Basic esters of substituted pyrimidine -4- carboxylic acids", J. Can.Chem 34: 1445 .

27. A. Foroumadi, A. Asadipour, M. Mirzaei, J. Karimi, S. Emami (2002) "Antituberculosisagents.V. Synthesis, evaluation of in vitro anti Tuberculosis activity and cytotoxicity of some 2-(5-nitro-2-furyl)-1,3,4-thiadiazole derivatives", IL Farmaco 57: 765-769.

28. H.L.Yale, K.Losee, J.Martins, M.Holsing, F.M. Perry et al. (1953) "Chemotherapy of experimental tuberculosis. VIII. The Synthesis of acid hydrazides, their derivatives and related compounds", J. Am. Chem. Soc 75: 1933-1942.

29. A.Cansiz, M.Koparir, A.Demirdağ (2004) "Synthesis of some new4,5- substituted -4H-1,2,4- triazole -3- thiol derivatives", Molecules 9: 204-212.

30. A.Hussain, K.Sharba, R.H.Al-Bayati, M.Aouad, N.Rezki (2005) "Synthesis of Oxadiazoles, Thiadiazoles and Triazoles derived from Benzo[b]thiophene", Molecules 10: 1161-1168.

31. S.Ramachandran, P.K. Sreekumar (2011) "Synthesis, characterization and antibacterial evalution of $2(5 \mathrm{H})$-Furanone derivatives from highly functionalized Mucobromic acid", Int. Pharm. Pharm. Sci 3: 225-228.

32. B. Daniel Thomas, P. Global, D. Ann Arber (2004) Process for preparing functionalized gama-butyro lactones from mucochloric acid EP1537095B1, WO2004/020424.

33. Berand S, DE, Frank H, Mannheim DE, Norbert gand Woms DE.US patent (2008) Preparation of 2-amino thiazole-5carboxylic acid derivatives Patent numberUS7.408,069B2.

34. I. Vogel (1956) "Practical Organic Chemistry", $3^{\text {rd }} 401: 369,477$.

35. K.Clark, (1954), "The synthesis of 1, 2, 4- oxadiazoles", J.Chem.Soc. 4251.

36. H.W.Moore, L. A Hernandaz, D.M.Kunert, F.Mercer, A.Sing (1981) "Anew synthetic route to 2-azetidinones ring contraction of 4- azido-2-pyrrolinones to 3- cyano-2-azetidinones”, J. Am. 
Chem. Soc 103: 1769-1777.

37. A.Omairi, (2001) "Synthesis of some new comparing compounds and the study of their biological activity", M.Sc. Thesis, University of Mosul, Iraq.
38. Weller III, N.Harold, A. Michael (1993) "Oxadiazinone substituted indole and benzimidazole derivatives", United States Patent 5: 236-916.
Copyright: (C2018 M.S.Al-Ajely. This is an open-access article distributed under the terms of the Creative Commons Attribution License, which permits unrestricted use, distribution, and reproduction in any medium, provided the original author and source are credited. 